\title{
A New Flow Cytometry Technique to Identify Phaeomoniella chlamydospora Exopolysaccharides and Study Mechanisms of Esca Grapevine Foliar Symptoms
}

\author{
A. Andolfi, A. Cimmino, and A. Evidente, Dipartimento di Scienze del Suolo, della Pianta, dell' Ambiente e delle \\ Produzioni Animali, Università di Napoli Federico II; M. Iannaccone and R. Capparelli, Facoltà di Scienze Biotec- \\ nologiche, Università di Napoli Federico II, Via Università 100, 80055 Portici, Italy; and L. Mugnai and \\ G. Surico, Dipartimento di Biotecnologie Agrarie - Patologia Vegetale, Università degli Studi di Firenze, Piazzale \\ delle Cascine 28, 50144 Firenze, Italy
}

\begin{abstract}
Andolfi, A., Cimmino, A., Evidente, A., Iannaccone, M., Capparelli, R., Mugnai, L., and Surico, G. 2009. A new flow cytometry technique to identify Phaeomoniella chlamydospora exopolysaccharides and study mechanisms of esca grapevine foliar symptoms. Plant Dis. 93:680-684.

A flow cytometry technique that unequivocally identifies some of the toxic metabolites produced by Phaeomoniella chlamydospora, one of the main fungal pathogens causing esca disease of grapevine (Vitis vinifera), was developed. Antibodies raised against exopolysaccharides (EPS) metabolites produced by $\mathrm{Pa}$. chlamydospora that have been reported to be phytotoxic-were used as antigen to immunize rats. The specificity of these antibodies was assayed by flow cytometry against $\mathrm{Pa}$. chlamydospora polysaccharides and against EPS with a different structure isolated from other phytopathogenic fungi, including Phaeoacremonium aleophilum and the Botryosphaeriaceae species Neofusicoccum luteum and N. parvum. Using this method, Pa. chlamydospora polysaccharides were detected in the symptomatic leaves of esca-affected grapevines, while healthy and asymptomatic leaves from both healthy and diseased vines did not produce a binding reaction. This method potentially could be used to develop a simple kit to study the mechanisms underlying the development of esca foliar symptoms and to indirectly assess the presence of $P a$. chlamydospora in grapevine material.
\end{abstract}

Esca is one of the most important diseases of grapevine (Vitis vinifera L.) in almost all areas where vines are grown. The disease affects the woody tissues (trunk and branches), which show brown streaking and often also white rot of the wood in the trunk or main branches, and sudden wilting (apoplexy) that eventually leads to the death of the vine (17). The shoots, leaves, and berries are also affected. The leaf symptoms are the most characteristic, consisting of irregular light green or chlorotic areas between the veins or along the leaf margin, which gradually spread from the basal to the distal part of the shoot. As the chlorotic tissue turns yellow-brown or red-brown, the diseased leaves assume a tiger-stripe pattern $(17,25)$. Fruit symptoms include tiny brown spots and sometimes withering of the berries. Of all these symptoms, the most typical and striking is the develop-

Corresponding author: A. Evidente

E-mail: evidente@unina.it

Accepted for publication 20 March 2009.

doi:10.1094/PDIS-93-7-0680

(C) 2009 The American Phytopathological Society ment of tiger stripes on the leaves, but esca can produce a wide spectrum of leaf symptoms and discolorations, some of which happen to be identical with the symptoms of other grapevine disorders (24). Consequently, the visible symptoms of esca are not always diagnostic and in such cases should be confirmed by other means.

Esca is a complex disease in which a number of different fungi have been reported as causal agents, the principal ones being Phaeomoniella chlamydospora (W. Gams, Crous, M.J. Wingfield \& L. Mugnai) Crous \& W. Gams, Phaeoacremonium aleophilum W. Gams, Crous, M.J. Wingfield \& L. Mugnai, and Fomitiporia mediterranea M. Fischer (16,17,25). Pa. chlamydospora is a tracheomycotic pathogen that is associated with all the syndromes in the esca complex (brown wood streaking of the rootstock, Petri disease, young esca), while $F$. mediterranea and other species of basidiomycetes are agents of white rot $(11,16,17,24,25)$.

One peculiar characteristic of esca is that the expression of leaf symptoms is intermittent and may not appear in every growing season. They can suddenly fail to show up one year or even for a number of years, during which time the vinealthough still diseased-is asymptomatic and to all intents and purposes indistinguishable from a healthy vine $(13,14,23)$.

This discontinuity of leaf symptoms makes it almost impossible to determine the true incidence of esca in a vineyard at any given time.

Both the leaf and berry symptoms of esca are suspected to be caused by phytotoxins produced by $P m$. aleophilum and/or $P a$. chlamydospora. These phytotoxins have been isolated from culture filtrates of the two fungi and have been identified as scytalone, isosclerone, and pullulans (exopolysaccharides [EPS]) $(2,9,22)$.

The objective of this study was to develop a rapid and specific method for the production of polyclonal antibodies against $P a$. chlamydospora toxins in order to detect the presence of the toxin produced by $P a$. chlamydospora in the leaves of escaaffected grapevines. These antibodies could also be used as tools to investigate the manner in which the foliar symptoms of esca are induced. We describe here an immunofluorescence procedure based on flow cytometry and antibodies developed against the Pa. chlamydospora exopolysaccharide hapten.

\section{MATERIALS AND METHODS}

Fungal strains and culture conditions. The Pa. chlamydospora isolate used in this study was obtained from esca-diseased grapevines ( $V$. vinifera) in Italy, and is deposited as the Pa. chlamydospora type strain (CBS 229.95) at the Centraalbureau voor Schimmelcultures (Utrecht, The Netherlands). In addition, five other isolates of Pch (PVFi 7, 31, 135, 551, and 606) and one isolate of Pm. aleophilum (PVFi-G1) obtained from different grapevine cultivars and countries, and belonging to the collection of the Dipartimento di Biotecnologie Agrarie-Patologia Vegetale, Università degli Studi di Firenze, were used. Cultures were maintained in slants of malt agar at $4{ }^{\circ} \mathrm{C}$ and grown to produce metabolites in stationary liquid culture, as described by Evidente et al. for Pm. aleophilum (9). Other strains included for comparison were P. foeniculi Du Manoir \& Vegh (5), P. exigua var. heteromorpha 
(Schulzer \& Sacc.) Noordel. \& Boerema (3), Neofusicoccum luteum (Pennycook \& Samuels) Crous, Slippers \& A.J.L. Phillips, and $N$. parvum (Pennycook \& Samuels) Crous, Slippers \& A.J.L. Phillips (15). For data on strains and growth conditions of Phomopsis foeniculi, Phoma exigua var. heteromorpha, and Neofusicoccum luteum and $N$. parvum, refer to references 5,3 , and 15 .

Plant material. Vine leaves with interveinal, marginal discoloration and necrosis, and acropetal symptom gradient (Fig. 1A to C), were collected in July 2007 from a 14-year-old cv. Cabernet Sauvignon vineyard in the province of Florence, Italy, which had been monitored for esca symptoms for 4 years. Three to five leaves per each health class, 15 leaves per plant, were collected. At the same time, healthy control leaves were also collected in the same vineyard from vines that had not shown esca foliar symptoms in any of the survey years (2003 to 2006) or in 2007 (vines that have been asymptomatic for so long are generally presumed to be healthy).

Leaves were harvested at the end of July from two asymptomatic vines (no. 61 and 62) and from eight symptomatic vines (no. $1,2,3,6,44,47,58$, and 141) that showed typical esca symptoms (tiger-striped necrosis and chlorosis on the blade). The leaves were selected as follows: (AAA) asymptomatic leaves from asymptomatic shoots on asymptomatic vines; (AAD) asymptomatic leaves from asymptomatic shoots on symptomatic vines; (ACD) asymptomatic leaves close to symptomatic leaves growing on the same shoot; (AFD) asymptomatic leaves distal to symptomatic leaves growing on the same shoot; (D) symptomatic leaves with incipient signs (small yellowish chlorotic spots); and (S) symptomatic leaves with tiger-striped coloration but no necrosis.

Preparation of native EPS from fungal culture filtrates. The pooled culture filtrates of Pa. chlamydospora (1.7 liters) was brought to $\mathrm{pH} 4.0$ with $2 \mathrm{M} \mathrm{HCl}$ and extracted four times with $700 \mathrm{ml}$ of ethyl acetate each time. The combined organic extracts were dried on anhydrous sodium sulfate and evaporated under reduced pressure, yielding a dark-brown oily residue containing the naphthalenone pentaketides scytalone and isosclerone (9). The aqueous phase resulting from the acid extraction was freeze-dried, dissolved in $100 \mathrm{ml}$ of ultrapure Milli-Q water, cooled to $4^{\circ} \mathrm{C}$, mixed by stirring with 5 volumes $(500 \mathrm{ml})$ of cold absolute ethanol, and left overnight at $-20^{\circ} \mathrm{C}$. The precipitate was separated by centrifugation at 7,000 rpm for $45 \mathrm{~min}$ at $4^{\circ} \mathrm{C}$. The precipitate was dissolved in 90 $\mathrm{ml}$ of ultrapure Milli-Q water and reprecipitated with $450 \mathrm{ml}$ of cold absolute ethanol as described above. The resulting precipitate was dissolved in $200 \mathrm{ml}$ of ultrapure Milli-Q water and dialyzed using Spectra/Por molecular porous membrane tubing with a 3,500-Da cutoff point (Spectrum Medical Industries Inc., Houston, TX, USA). Tubes were immersed in 10 volumes of distilled water for $48 \mathrm{~h}$ at $10^{\circ} \mathrm{C}$, with water being exchanged every 6 h. After dialysis, the tube contents were recovered and lyophilized to obtain the native EPS (400.5 mg).

The same procedure was applied to the culture filtrates $(100 \mathrm{ml})$ of the other $P a$. chlamydospora strains (PVFi 7, 31, 135, 551, and 606) and Pm. aleophilum strain PVFi G-1 (6.5 liters), to obtain native EPS $(31.4,31.5,20.5,16.5,19.1$, and $375.1 \mathrm{mg}$, respectively). None of these culture filtrates had undergone the acid procedure to extract the lipophilic toxins. For information on extraction of the EPS from culture filtrates of $P$. foeniculi and $P$. exigua var. heteromorpha and from $N$. luteum and $N$. parvum, refer to references 5,8 , and 15 .

Extraction of polysaccharides from grapevine leaves. Fresh leaf samples were weighed (range: 0.56 to $1.19 \mathrm{~g}$ ), frozen $\left(-20^{\circ} \mathrm{C}\right)$, ground, and homogenized with $20 \mathrm{ml}$ of phosphate buffer $(1.36 \mathrm{~g} /$ liter $\mathrm{K}_{2} \mathrm{H}_{2} \mathrm{PO}_{4}$ and $1.24 \mathrm{~g} /$ liter $\left.\mathrm{K}_{2} \mathrm{HPO}_{4}\right), \mathrm{pH}$ 6.0 , in a blender (Waring Products Division, New Hartford, CT, USA), and the homogenate was then lyophilized. The lyophilized residue was dissolved in $5 \mathrm{ml}$ of distilled Milli-Q water and 10 volumes $(50 \mathrm{ml})$ of ethanol with stirring. The suspension was kept in the dark at $4^{\circ} \mathrm{C}$ for 24 $\mathrm{h}$, after which it was centrifuged at $4^{\circ} \mathrm{C}$ at $7,000 \mathrm{rpm}$ for $40 \mathrm{~min}$, and the supernatant was collected and evaporated under vacuum. The residue was lyophilized, and residues ranged from 22.6 to $126.6 \mathrm{mg}$.
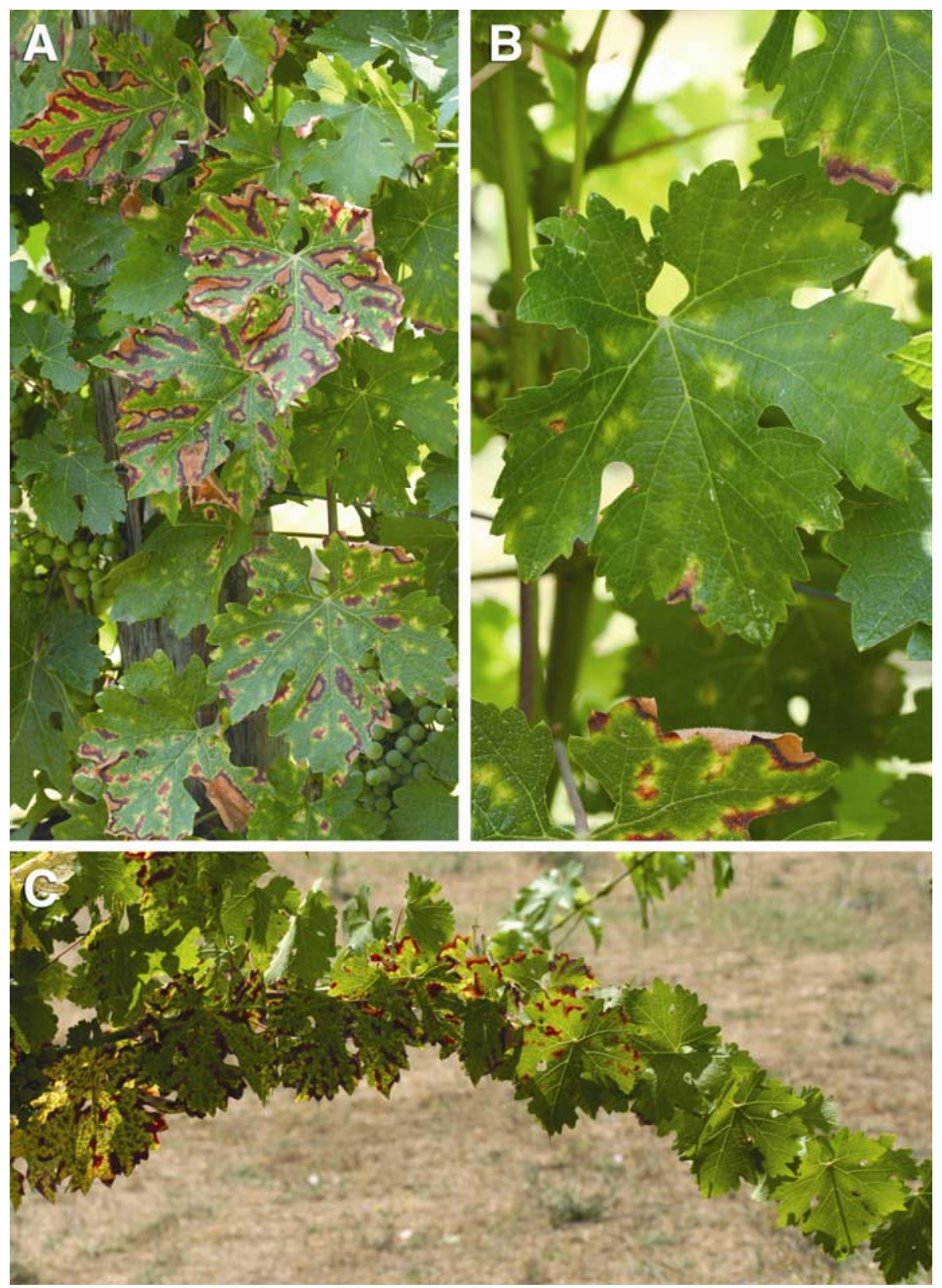

Fig. 1. Esca-diseased grapevine leaves with tiger-stripe discoloration: A, leaves showing different stages of the symptoms; $\mathbf{B}$, a leaf showing the initial interveinal chlorotic spots; $\mathbf{C}$, a shoot showing the acropetal symptom gradient. 
The UV spectra of these extracts were recorded in water on a Perkin-Elmer Lambda 25 UV/Vis spectrophotometer.

Preparation of antibodies. Native EPS from Pa. chlamydospora (CBS.229.95 strain) were used to immunize Fisher rats following the method reported by Del Sorbo et al. (6). Specifically, two approximately 3-month-old New Zealand female rats were injected four times at 1-week intervals with $1 \mathrm{mg}$ of $P$ ch EPS dissolved in $1 \mathrm{ml}$ of PBS $(0.15 \mathrm{M}$ sodium phosphate, $\mathrm{pH} 7.2$, containing $0.85 \% \mathrm{NaCl}$ ). The first injection consisted of the antigen solution emulsified with an equal volume of
Freund's adjuvant (Sigma Chemical Co., St. Louis, MO, USA) immediately before use. Blood samples $(5 \mathrm{ml})$ were collected from the marginal vein of the ear 10 days before the first injection to obtain preimmune serum as a control and 10 days after the last injection. Sera volumes $(2.5 \mathrm{ml})$ were stored at $-20^{\circ} \mathrm{C}$.

Standard cytofluorimetric test. To attach EPS to latex particles (10 mm diameter), $10^{4}$ latex particles (Polyscience, Eppelheim, Germany) per tube were incubated overnight at $4^{\circ} \mathrm{C}$ in shake culture with $1 \mathrm{ml}$ of borate buffer $(0.2 \mathrm{M}, \mathrm{pH} 8.5)$ containing $50 \mu \mathrm{g}$ of EPS obtained from
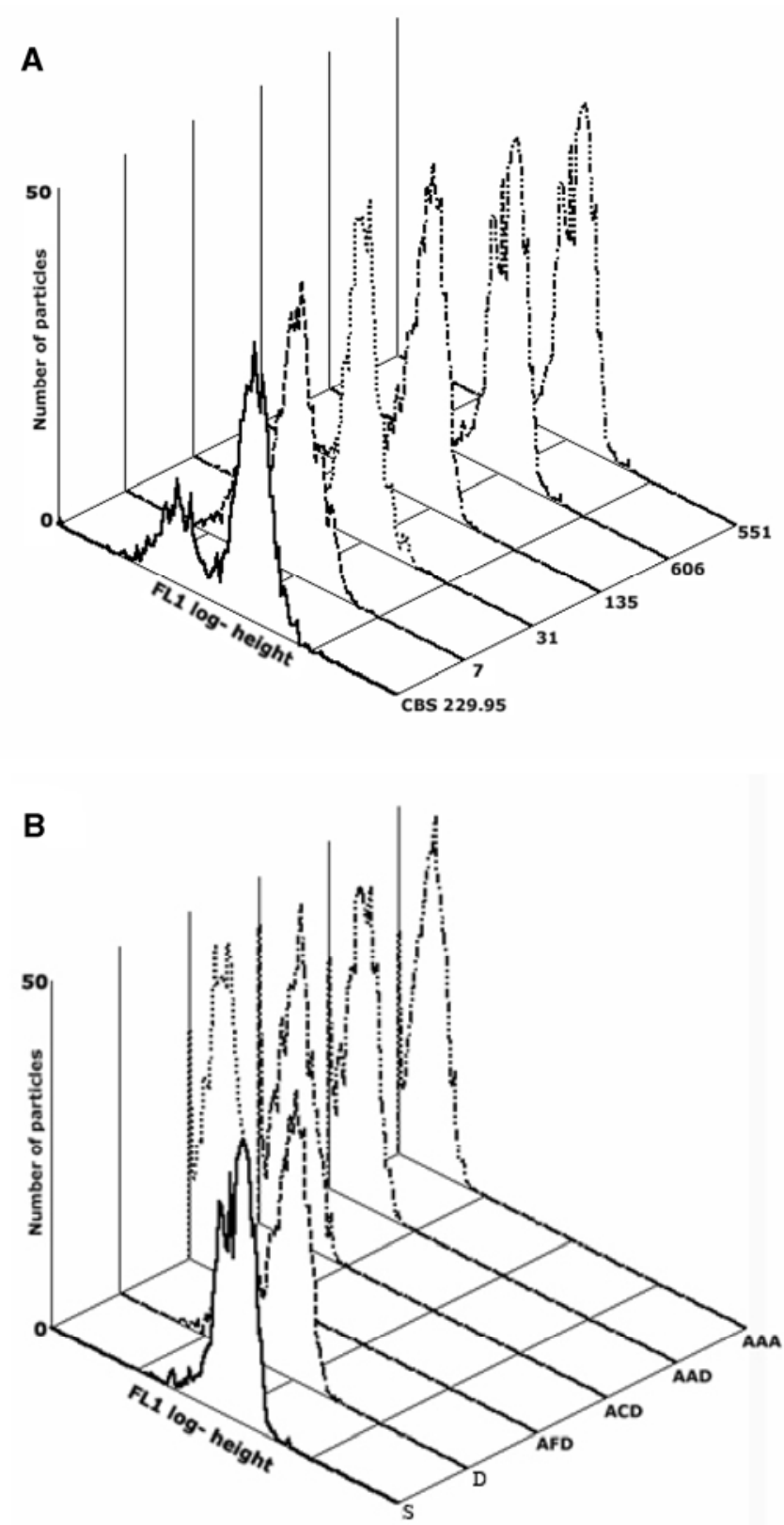

Fig. 2. A, Cytofluorimetric profiles of Phaeomoniella chlamydospora extracts from strains CBS $229.95,7,31,135$, and 606. B, Cytofluorimetric profile of leaf extracts of asymptomatic vine leaves from asymptomatic vine no. 61 (AAA) and from the symptomatic vine no. 58. Leaf extracts had been obtained from (AAD) asymptomatic leaves collected from the asymptomatic shoot of the symptomatic vine; from asymptomatic leaves growing on the same shoot near (ACD) or distal (AFD) to a symptomatic leaf; (D) from symptomatic leaves with incipient symptoms (small yellowish chlorotic spots); and $(\mathrm{S})$ from leaves from the same vine with tiger-stripe discoloration but no necrosis. Axis of abscissa is FL- $\log$ height; axis of ordinate is number of particles.

each tested fungus. The remainder of this procedure was carried out at room temperature. The mixture was centrifuged and the pellet was incubated for 30 min with $2 \%$ ( $\mathrm{vol} / \mathrm{vol}$ ) blocking milk diluted with PBS (100 $\mu \mathrm{l})$ (Waring Products). The particles were then washed with PBS and incubated for $3 \mathrm{~h}$ with anti-EPS serum diluted 1:25, 1:50, and 1:100 in PBS, washed with PBS (two times), and incubated with $100 \mu \mathrm{l}$ of goat anti-rat immunoglobulin labeled with fluorescein diluted 1:600 (Sigma) for $1 \mathrm{~h}$. Particles were washed once with PBS and analyzed using a flow cytometer (FACScan, BeaconDickinson, San Jose, CA, USA) equipped with a $15-\mathrm{mW}$, air-cooled 488-nm argon ion laser. Green fluorescence (FITC) was collected through a 530/30 $\mathrm{nm}$ bandpass filter. Data on 3,000 events were collected for each sample, stored in list mode, and then analyzed using the Consort 32 system (Hewlett-Packard, Sunnyvale, CA, USA). Forward scattering (FSC) and side scattering (SSC) were analyzed on a linear scale, and FITC fluorescence on a logarithmic scale. No gates were set around the particles. The results are presented as the mean channel fluorescence of the sample minus the mean channel control (autofluorescence of secondary antibodies with antigens). Autofluorescence (the average fluorescence intensity of the internal control of machine) varied between 1.5 and $2 \%$. Negative controls (asymptomatic leaves) were treated similarly except that extracts were incubated with PBS only without rat anti-EPS serum. Each sample was analyzed in triplicate, and the experiments were repeated three times.

\section{RESULTS}

Production and specificity of $P a$. chlamydospora EPS antibodies. The native EPS obtained by fractionated ethanol precipitation from the $\mathrm{Pa}$. chlamydospora culture filtrates produced specific antibodies when they were used as antigen to immunize rats. As expected, the position on the $\mathrm{x}$-axis of the cytofluorimetric profile for EPS obtained from the standard $\mathrm{Pa}$. chlamydospora strain (CBS 229.95) indicated binding activity with the antibodylabeled beads (Fig. 2A). The positions on the $\mathrm{x}$-axis of the profiles for the other $\mathrm{Pa}$. chlamydospora strains $(7,31,135,551$, and 606) (Fig. 2A) indicated similar recognition by the antibody-labeled beads. There was no recognition with the control EPS from $P$. foeniculi and $P$. exigua var. heteromorpha, and no recognition was observed when testing the EPS obtained from $P m$. aleophilum (the other vascular pathogen involved in esca disease) or from $N$. luteum and N. parvum (data not shown). The latter are agents of wood necrosis and bark canker of grapevine (26), on which preliminary chemical investigations have been carried out (15). 
Cytofluorimetric tests on the extracts from symptomatic and asymptomatic grapevine leaves. The weight of the lyophilized ethanol extracts from both the symptomatic and the asymptomatic leaves of esca-diseased vines, and from the asymptomatic leaves of healthy vines, ranged between 22.6 and $126.6 \mathrm{mg}$. Their UV spectra showed absorbance maxima in the range of 251 to $266 \mathrm{~nm}$, which did not interfere with the cytofluorimetric tests. The results of cytofluorimetric tests on both the hapten (Pa. chlamydospora EPS) and the leaf extracts were obtained using the optimal dilution (1:25) of the antibodies. The test, which is a qualitative assay, was carried out using a fixed amount of leaf extract $(100 \mu \mathrm{g})$. The sensitivity of the method was determined by using different concentrations of purified $P a$. chlamydospora EPS (5 to $100 \mu \mathrm{g}$ ). With $5 \mu \mathrm{g}$ of $P c h$ EPS, a change of $16.3 \pm 0.2$ in fluorescence intensity relative to the negative control was observed, while with amounts lower than $5 \mu \mathrm{g}$ there was no recognition (data not shown); consequently, the detection limit for purified Pa. chlamydospora EPS was set at $5 \mu \mathrm{g}$. No recognition occurred with amounts of leaf extract lower than $100 \mu \mathrm{g}$, whereas when double the amount of leaf extract $(200 \mu \mathrm{g})$ was tested there was no difference from the result seen with $100 \mu \mathrm{g}$ (data not shown).

When the leaf ethanol extracts were tested, only the extracts of leaves with esca symptoms were recognized by the antibodies (Table 1, columns D and S). Strong recognition was manifested by fluorescence values ranging from 9.1 to 9.8 for ethanol extracts from the leaves with incipient symptoms (Table 1, column D) and values of 16.1 to 16.5 for extracts from highly symptomatic leaves (Table 1 , column S) of vines 1, 2, 3, 6, 44, 47, 58, and 141 , which showed different levels of typical esca symptoms. In contrast, extracts from asymptomatic leaves from asymptomatic vines 61 and 62 (Table 1, column AAA) and asymptomatic leaves from symptomatic vines $1,2,3,6,44,47,58$, and 141 (Table 1, columns AAD, ACD, and AFD) all had values $<0.7$, which indicated no recognition by the antibodies.

The positions on the $\mathrm{x}$-axis of the cytofluorometric profiles for extracts of asymptomatic leaves taken from the asymptomatic vines 61 (Fig. 2B, sample AAA) and 62 (data not shown) indicated no recognition by the antibody-labeled beads. The positions of profiles showed a similar lack of recognition with the extracts of asymptomatic leaves from asymptomatic shoots of symptomatic vine 58 (Fig. 2B, sample $\mathrm{AAD}$ ), and the extracts of asymptomatic leaves either near or distal to symptomatic leaves growing on the symptomatic shoot of diseased vine 58 (Fig. 2B, samples ACD and AFD). In contrast, when the extracts of leaves with incipient chlorotic symptoms or leaves with fully developed symptoms from diseased vine 58 were tested (Fig. $2 \mathrm{~B}$, samples $\mathrm{D}$ and $\mathrm{S}$, respectively), the position of the profiles on the $\mathrm{x}$-axis indicated there was strong recognition by the antibodies.

\section{DISCUSSION}

As expected, the antibodies raised against Pa. chlamydospora EPS immunogens reached high levels in rats (19) and in our tests showed a very high specificity with the injected antigen compared to the specificity toward EPS obtained from five other pathogenic fungi.

The phytotoxic fungal EPS that were used for comparison with the Pa. chlamydospora EPS in our cytofluorimetric tests were isolated from Pm. aleophilum, P. foeniculi, and $P$. exigua var. heteromorpha and from two Botryosphaeriaceae species that are also agents of wood diseases of grapevine $(15,26)$. The polysaccharides from $P$. foeniculi and from $P$. exigua var. heteromorpha had previously been found to consist of a mixture of a galactan, a branched mannan (5), and a phosphorylated polysaccharide containing $70 \%$ mannose and lower percentages of galactose and glucose, respectively (8). On the other hand, in the first study to focus on the isolation and chemical characterization of the phytotoxic metabolites produced by five phytopathogenic Botryosphaeriaceae species that are agents of grapevine trunk diseases, we recently showed that all the strains tested produced high molecular weight hydrophilic toxins, which in the case of $N$. luteum and $N$. parvum were EPS. In the latter fungus, preliminary GCMS analyses indicate that the EPS consist essentially of glucose, galactose, and mannose (15). The phytotoxic polysaccharides produced by $\mathrm{Pa}$. chlamydospora and $\mathrm{Pm}$. aleophilum contain a mixture of $\alpha$-glucans of different molecular weights, which have up to now been described as pullulans $(2,22)$.

Results of our antibody studies suggested that the EPS from Pm. aleophilum differ in structure from those produced by $P a$. chlamydospora and deserve to be more thoroughly investigated. Further studies are now underway, and the preliminary results are in agreement with the cytofluorimetric data reported here, where the antibodies raised against the $P a$. chlamydospora EPS showed the highest binding activity with the immunogen while not recognizing the EPS of Phomopsis foeniculi, Phoma exigua var. heteromorpha, $N$. luteum, N. parvum, and Pm. aleophilum.

There are several possible explanations for the appearance of esca leaf symptoms in grapevine (17), but the most likely explanation is that such symptoms are caused by an accumulation of extracellular fungal toxin(s) in the vine leaves (7). EPS produced in vitro by $P a$. chlamydospora and either absorbed at very low doses by detached vine leaves or injected into the woody tissues of vine shoots have been found to reproduce in vivo foliar symptoms that are very similar to esca foliar symptoms $(21,22)$. It has been postulated that these toxins are produced in wood colonized by $P a$. chlamydospora, from where they migrate into the vessels of the

Table 1. Detection of Phaeomoniella chlamydospora exopolysaccharides (Pch-EPS) in extracts of symptomatic and asymptomatic grape leaves by the cytofluorimetric test

\begin{tabular}{|c|c|c|c|c|c|c|}
\hline \multirow[b]{2}{*}{ Vine no. } & \multicolumn{6}{|c|}{ Relative change in sample fluorescence ${ }^{a}$} \\
\hline & $\mathbf{A} \mathbf{A} \mathbf{A}^{\mathbf{b}}$ & $\mathbf{A} \mathbf{A} \mathbf{D}^{\mathbf{b}}$ & $\mathbf{A C D}^{\mathbf{b}}$ & $\mathbf{A F D}^{\mathbf{b}}$ & $\mathbf{D}^{\mathbf{b}}$ & $\mathbf{S}^{\mathbf{b}}$ \\
\hline 1 & $\Omega^{c}$ & $0.5 \pm 0.1$ & $0.4 \pm 0.2$ & $0.4 \pm 0.3$ & $9.5 \pm 0.3$ & $16.1 \pm 0.4$ \\
\hline 2 & - & $0.4 \pm 0.2$ & $0.2 \pm 0.1$ & $0.5 \pm 0.2$ & $9.1 \pm 0.4$ & $16.2 \pm 0.4$ \\
\hline 3 & - & $0.3 \pm 0.2$ & $0.4 \pm 0.3$ & $0.3 \pm 0.1$ & $9.8 \pm 0.5$ & $16.3 \pm 0.5$ \\
\hline 6 & - & $0.5 \pm 0.3$ & $0.5 \pm 0.3$ & $0.5 \pm 0.3$ & $9.5 \pm 0.3$ & $16.2 \pm 0.7$ \\
\hline 44 & - & $0.3 \pm 0.1$ & $0.4 \pm 0.1$ & $0.4 \pm 0.2$ & $9.3 \pm 0.4$ & $16.4 \pm 0.6$ \\
\hline 47 & - & $0.4 \pm 0.3$ & $0.5 \pm 0.3$ & $0.6 \pm 0.4$ & $9.5 \pm 0.5$ & $16.2 \pm 0.7$ \\
\hline 58 & - & $0.3 \pm 0.2$ & $0.3 \pm 0.2$ & $0.3 \pm 0.2$ & $9.4 \pm 0.2$ & $16.5 \pm 0.3$ \\
\hline 141 & - & $0.5 \pm 0.2$ & $0.3 \pm 0.2$ & $0.5 \pm 0.2$ & $9.8 \pm 0.4$ & $16.5 \pm 0.5$ \\
\hline 61 & $0.3 \pm 0.2$ & - & _c & _c & _c & c \\
\hline 62 & $0.4 \pm 0.2$ & - & - & - & - & - \\
\hline
\end{tabular}

${ }^{a}$ Fluorescence values (mean channel fluorescence of the sample less the mean channel fluorescence of the control) are the average of all experiments \pm standard deviation. Each experiment used $100 \mu \mathrm{g}$ of extract with 40,000 antibody-labeled particles.

${ }^{b}$ AAA: asymptomatic leaves from an asymptomatic vine; AAD: asymptomatic leaves from the asymptomatic shoot of a symptomatic vine; ACD: asymptomatic leaves growing near a symptomatic leaf on the same shoot; AFD: asymptomatic leaves distal to a symptomatic leaf growing on the same shoot; D: leaves with incipient symptoms (small yellowish chlorotic spots); and S: symptomatic leaves with tiger-stripe discoloration but no necrosis.

c Samples not evaluated. 
vine trunks and branches and are then transported upward by the transpiration stream $(1,17,20,22,24)$. If and when they reach an active concentration in the leaves, symptoms will start to appear. The fact that EPS in symptomatic leaves is of the same type as the EPS produced in vitro by $P a$. chlamydospora supports the toxigenic origin of the foliar symptoms of esca.

EPS extracts from leaves with incipient chlorotic symptoms and with interveinal and marginal discoloration and necrosis were strongly recognized by the anti-EPS antibodies, whereas leaf extracts from asymptomatic leaves collected both from healthy vines (i.e., plants that had not shown esca foliar symptoms in any of the 4 years surveyed) and from diseased vines were not so recognized. Unexpectedly, however, binding activity was also not detected in extracts from asymptomatic leaves growing on symptomatic shoots near symptomatic leaves. Here it should be noted that alteration of the photosynthetic apparatus as a consequence of the disease can be detected in the leaves at least 15 days before initial symptom appearance $(4,12,18)$. It is also known that esca is characterized by an acropetal symptom gradient at shoot level. It was therefore expected that the accumulation of $\mathrm{Pa}$. chlamydospora EPS would follow the same pattern, so that they would also be detectable in the asymptomatic leaves growing in close proximity to leaves with symptoms; these leaves would still be asymptomatic but would presumably start showing symptoms in a short time (10). But the failure to detect any binding activity in these leaves does not invalidate the research work. The reason why EPS were not detected in these leaves may be simply that the leaves were examined when the concentration of Pa. chlamydospora EPS was still below the minimum detectable threshold by the method of analysis used. It is also possible, however, that the leaves that were asymptomatic when they were collected, and that were near, or distal, to symptomatic leaves, would never become symptomatic at all.

In conclusion, this is the first unmistakable demonstration of the presence of a metabolic product of $P a$. chlamydospora in the symptomatic leaves of esca diseased vines. This finding supports the hypothesis that the mechanism of foliar symptom formation is related to phytotoxic activity of Pa. chlamydospora exopolysaccharides. Data in support of this hypothesis would be a demonstration of a gradient of EPS that parallels the increasing severity of symptoms seen in leaves progressing to the tip of the vine. We also need to improve the sensitivity of EPS detection so that the antibodies can be utilized to diagnosis esca in the absence of symptoms, and to show the presence of $P a$. chlamydospora in the wood in cases in which the plant shows atypical foliar symptoms. Work is in progress on these matters.

\section{ACKNOWLEDGMENTS}

This study was commissioned by ARSIAToscana (Regional Agency for Development and Innovation in Agriculture and Forestry-Tuscany) on behalf of 14 regional governments and one autonomous province, and was funded by the Italian Ministero per le Politiche Agricole e Forestali (Ministry for Agriculture and Forestry) to implement the inter-regional project "Esca of grapevine: Research and experiments in the nursery and in the field for prevention and cure." Contribution DISSPAPA 187.

\section{LITERATURE CITED}

1. Bruno, G., and Sparapano, L. 2006. Effects of esca-associated fungi on Vitis vinifera L.: II. Characterization of biomolecules in xylem sap and leaves of healthy and diseased vines. Physiol. Mol. Plant Pathol. 69:195-208.

2. Bruno, G., and Sparapano, L. 2006. Effects of three esca-associated fungi on Vitis vinifera L.: I. Characterization of secondary metabolites in culture media and host responses to pathogen in calli. Physiol. Mol. Plant Pathol. 69:209223.

3. Capasso, R., Evidente, A., Randazzo, G., Ritieni, A., Bottalico, A., Vurro, M., and Logrieco, A. 1987. Isolation of cytochalasins A and B from Ascochyta heteromorpha. J. Nat. Prod. 50:989-990.

4. Christen, D., Schonmann, S., Jermini, M., Strasser, R. J., Défago, G., and Wagschal, I. 2007. Characterization and early detection of grapevine (Vitis vinifera) stress responses to esca disease by in situ chlorophyll fluorescence and comparison with drought stress. Phytopathol. Mediterr. 46:112.

5. Corsaro, M. M., De Castro, C., Evidente, A., Lanzetta, R., Molinaro, A., Mugnai, L., Parrilli, M., and Surico, G. 1998. Chemical structure of two phytotoxic exopolysaccharides produced by Phomopsis foeniculi. Carbohydr. Res. 308:349-357.

6. Del Sorbo, G., Evidente, A., and Scala, F. 1994. Production of polyclonal antibodies from cyclopaldic acid, a major phytotoxic metabolite produced by the plant pathogen Seiridium cipressi. Nat. Toxins 2:136-140.

7. Edwards, J., Salib, S., Thomson, F., and Pascoe, I. G. 2007. The impact of Phaeomoniella chlamydospora infection on the grapevine's physiological response to water stress Part 2: Cabernet Sauvignon and Chardonnay. Phytopathol. Mediterr. 46:38-49.

8. Evidente, A., and Motta, A. 2001. Phytotoxins from fungi pathogenic for agrarian, forestal and weedy plants. Pages 473-525 in: Bioactive Compounds from Natural Sources. C. Tringali, ed. Taylor \& Francio, London.

9. Evidente, A., Sparapano, L., Andolfi, A., and Bruno, G. 2000. Two naphthalenone pentaketides from liquid cultures of Phaeoacremonium aleophilum, a fungus associated with esca of grapevine. Phytopathol. Mediterr. 39:162-168.

10. Felgueiras, M. R., Chicau, M. L., MoutinhoPereira, J. M., and Dias, A. C. P. 2007. Effects of esca disease on leaf gas exchanges of cv.
Alvarinho in a vineyard of the Portuguese Vinho Verde Region. Phytopathol. Mediterr. 46:119.

11. Fischer, M. 2006. Biodiversity and geographic distribution of basidiomycetes causing escaassociated white rot in grapevine: A worldwide perspective. Phytopathol. Mediterr. 45(Suppl.): S30-S42.

12. Fontaine, F., Boulay, M., Vaillant-Gaveau, N., and Clemént, C. 2007. Photosynthesis alteration before foliar esca expression. Phytopathol. Mediterr. 46:117.

13. Hewitt, W. B. 1957. Some manifestations of black measles of grapevines. Phytopathology 47:16.

14. Marchi, G., Peduto, F., Mugnai, L., Di Marco, S., Calzarano, F., and Surico, G. 2006. Some observations on the relationship of manifest and hidden esca to rainfall. Phytopathol. Mediterr. 45(Suppl.):S117-S126.

15. Martos, S., Andolfi, A., Luque, J., Mugnai, L., Surico, G., and Evidente, A. 2008. Production of phytotoxic metabolites of Botryosphaeriaceae causing decline on grapevines, with special interest in the species Neofusicoccum luteum and N. parvum. Eur. J. Plant Pathol. 121:451-461.

16. Mostert, L., Halleen, F., Fourie, P., and Crous, P. W. 2006. A review of Phaeoacremonium species involved in Petri disease and esca of grapevines. Phytopathol. Mediterr. 45(Suppl.): S12-S29.

17. Mugnai, L., Graniti, A., and Surico, G. 1999 Esca (black measles) and brown woodstreaking: Two old and elusive diseases of grapevines. Plant Dis. 83:404-417.

18. Mugnai, L., Peduto, F., Calamai, L., Mattii, G., Marchi, G., Surico, G., and Zini, E. 2007. Recent developments of research on the factors influencing symptom appearance in esca diseased grapevines in Italy. Phytopathol. Mediterr. 46:113.

19. Pazur, J. H. 2005 Anti-carbohydrate antibodies potentially useful for medical and technical applications. Recent. Devel. Carbohydr. Res. 2:1-16.

20. Petit, A.-N., Vaillant, N., Boulay, M., Clement, C., and Fontaine, F. 2006. Alteration of photosynthesis in grapevines affected by esca. Phytopathology 96:1060-1066.

21. Sparapano, L., Bruno, G., and Campanella, A. 2001. Interactions between three fungi associated with esca of grapevine, and their secondary metabolites. Phytopathol. Mediterr. 40(Suppl.):S417-S422.

22. Sparapano, L., Bruno, G., and Graniti, A 2000. Effects on plants of metabolites in culture by Phaeocremonium chlamydospora, $P$. aleophilum and Fomitiporia punctata. Phytopathol. Mediterr. 39:169-177.

23. Surico, G., Marchi, G., Braccini, P., and Mugnai, L. 2000. Epidemiology of esca in some vineyards in Tuscany (Italy). Phytopathol. Mediterr. 39:190-205.

24. Surico, G., Mugnai, L., Marchi, G. 2006. Older and more recent observations on esca: A critical overview. Phytopathol. Mediterr 45(Suppl.):S68-S86.

25. Surico, G., Mugnai, L., and Marchi, G. 2008 The esca disease complex. Pages 119-136 in Integrated Management of Diseases Caused by Fungi, Phytoplasma and Bacteria. A. Ciancio and K. G. Mukerji, eds. Springer, Heidelberg, Germany.

26. Van Niekerk, J. M., Fourie, P., Halleen, F., and Crous, P. W. 2006. Botryosphaeria spp. as grapevine trunk disease pathogens. Phytopathol. Mediterr. 45:S43-S54. 